\title{
Patterns of oviducal motility in the cow during the oestrous cycle*
}

\author{
W. A. Bennett†, T. L. Watts $\uparrow$, W. D. Blair $\ddagger$, S. J. Waldhalm§ and \\ J. W. Fuquay† \\ $\dagger$ Dairy Science Department, $\ddagger$ Agricultural and Biological Engineering Department, and $\S$ College of \\ Veterinary Medicine, Mississippi State University, Mississippi State, MS 39762, U.S.A.
}

\begin{abstract}
Summary. Microtransducers sensitive to changes in internal diameter were chronically implanted in the oviducts of 5 dairy cows. Motility patterns were recorded throughout 9 oestrous cycles. Cyclic variations in patterns of motility were observed and compared with circulating concentrations of plasma progesterone. Luteal-phase motility patterns were of low amplitude and frequency. The frequency and amplitude of motility increased 3-5 days before behavioural oestrus. This activity consisted primarily of longitudinal muscle contractions, with an interspacing of circular muscle activity occurring during oestrus. Patterns of activity after oestrus were similar to those before oestrus, with activity decreasing 3-5 days after oestrus. Transducers implanted bilaterally in 2 animals permitted observation of asynchronous patterns between right and left oviducts. Preliminary data suggested a higher level of activity in the oviduct ipsilateral to the active ovary. These variations may be due to a local effect, possibly mediated by the functional ovary or the ovum.
\end{abstract}

Keywords: oviduct; motility; oestrous cycle; progesterone; cow

\section{Introduction}

Ovum transport through the oviduct consists of rapid transport through the ampulla, followed by a delay at the ampulla-isthmic junction (Eddy \& Black, 1974; Eddy et al., 1978). Segmentation caused by activity of circular muscle is reportedly a major factor in the movement of spermatozoa to the ampulla where fertilization occurs (Black \& Asdell, 1958). To understand better the role of oviducal motility in gamete transport, researchers have attempted to correlate changes in oviducal motility with the period of the oestrous cycle of the pig (Rodriguez-Martinez et al., 1982) and cow (Ruckebusch \& Bayard, 1975): the highest frequency of contractions occurred during oestrus and metoestrus, the periods associated with sperm and ovum transport respectively.

The details of oviducal function in gamete transport in the cow have not been extensively studied. In addition, the respective roles of the circular and longitudinal muscle layers in gamete transport and fertilization are not well defined. The purpose of this study was to characterize the patterns of circular and longitudinal muscle activity of the cow oviduct during the oestrous cycle.

\section{Materials and Methods}

Microtransducer system. The Silastic (Dow Corning, Midland, MI) 'doughnut' microtransducers used for this study were a modification of the original system developed for measuring motility of the rabbit oviduct (Blair et al.,

*Reprint requests to: Dr J. W. Fuquay, Dairy Science Department, Drawer DD, Mississippi State, MS 39762, U.S.A.

TPresent address: 203 Court St, Batesville, MS 38606, U.S.A. 
1976). These transducers possessed an unstressed diameter of $1.2 \mathrm{~mm}$ with implantation in the oviduct producing a prestressing of the device since they were slightly larger than the inside diameter of the oviduct. The transducers were thus able to respond to increases and decreases in the internal diameter of the oviduct.

Modifications in the fabrication of the transducer system were made to protect the leads from visceral movement. The principal modification involved a coiling of the lead wires around a Silastic rod of $2.16 \mathrm{~mm}$ o.d. which was then placed inside a Silastic tube of $1.98 \mathrm{~mm}$ i.d. $\times 3.18 \mathrm{~mm}$ o.d. This coiling of the lead wires around the filled tubing produced a spring-like effect which decreased lead breakage and extended the life of the transducers.

Surgical procedure. Surgical implantation of the transducers was accomplished by a standing laparotomy with an incision in the paralumbar fossa region following local anaesthesia. The uterus was palpated through the abdominal incision and retracted to the incision site to expose the uterotubal junction. A $0.5 \mathrm{~mm}$ diameter stainless-steel guidewire was passed through a puncture wound in the uterus $2 \mathrm{~cm}$ caudal to the uterotubal junction. The wire was then threaded cranially through the uterotubal junction and into the proximal $4-5 \mathrm{~cm}$ of the oviduct. The guidewire was pushed through the oviducal wall near the ampulla. A transducer was selected and attached to the guidewire by means of a loop of $6-0$ suture. The transducer was then gently pulled through the incision in the uterus, through the uterotubal junction, until the device was located $2-3 \mathrm{~cm}$ cranially to the junction. The suture loop was clipped and pulled free, leaving the transducer firmly implanted in the lumen of the oviduct. The transducer leads were anchored to the uterine horn at several sites with silk sutures. Animals were allowed a 1-week recovery period after surgery before motility data were collected.

Research animals and sampling schedule. Oviducal motility was measured in 5 cows (Table 1). Transducers were placed in both oviducts of all cows. In 3 cows, only 1 transducer remained functional long enough to record motility from all phases of the oestrous cycle. In 2 cows, the left and right transducers were functional for 2-3 cycles. Motility patterns were recorded for a total of 9 cycles. Although a transducer was functioning in Cow 421 for only 7 days, the timing of its function with the cycle permitted observations during 4 phases of the cycle. Oviducal motility was monitored for a minimum of $1 \mathrm{~h}$ daily from 3-5 days before oestrus until 5 days after oestrus with observations on alternate days for the remainder of the cycle. Stage of the cycle was based on observation of oestrous behaviour and concentration of progesterone in peripheral plasma.

Table 1. Details of cows studied

\begin{tabular}{lcccc}
\hline Cow no. & Breed & $\begin{array}{c}\text { Distance (cm) of } \\
\text { transducer from } \\
\text { uterotubal junction } \\
\text { (left/right) }\end{array}$ & $\begin{array}{c}\text { Days recorded } \\
\text { (left/right) }\end{array}$ & Cycles \\
\hline 179 & Jersey & $3 \cdot 0 / 2 \cdot 0$ & $51 / 51$ & $3 / 3$ \\
465 & Guernsey & $3 \cdot 5 / 2 \cdot 5$ & $34 / 34$ & $2 / 2$ \\
456 & Guernsey & $2-3 / 1 \cdot 0$ & $62 / 14$ & $2 / 0$ \\
210 & Jersey & $3-4 / 2 \cdot 0$ & $22 / 6$ & $1 / 0$ \\
421 & Guernsey & $1 \cdot 0 / 3 \cdot 0$ & $2 / 7$ & $0 / 1$ \\
\hline
\end{tabular}

Progesterone radioimmunoassay. Blood samples were collected after each recording session into heparin-treated tubes, centrifuged, and the plasma stored at $-20^{\circ} \mathrm{C}$ in plastic sample vials. Plasma progesterone concentrations were measured in a liquid-phase radioimmunoassay system based on that of Abraham et al. (1971). Progesterone was extracted from plasma with diethyl ether followed by direct assay of the extracts. Duplicate determinations were made for all samples, and all values were corrected for procedural losses. The mean percentage recovery of $[1,2,6,7$. ${ }^{3} \mathrm{H}(\mathrm{N})$ ]progesterone (New England Nuclear, Boston, MA) was $91.9 \%(n=3)$. The average coefficient of variation for the analysis of pooled cow plasma was $8.03 \%(n=6)$ within assays and $12.85 \%$ between assays. The antibody, donated by $\mathrm{Dr} \mathrm{H}$. Dobson (Dobson et al., 1972), exhibited a $0.06 \%$ cross-reactivity with corticosterone, and $<0.01 \%$ with all other steroids at $50 \%$ displacement. When $0.063,0.500$ and $2.500 \mathrm{ng}$ standard progesterone/tube were added to pooled plasma, corrected values of $0.057 \pm 0.011,0.494 \pm 0.610$ and $1.940 \pm 0.855 \mathrm{ng} /$ tube were obtained. This assay exhibited a sensitivity of $0.020 \mathrm{ng} / \mathrm{ml}$ plasma.

Statistical analyses. For the determination of peak frequency, a 10-min segment of motility data was selected according to the following criteria. (1) The first 10 min of recording from each session was routinely excluded. (2) Any segments with noted recording artefacts (i.e. animal movement, power transients) were excluded from the analysis. (3) A subjective assessment was made of the remaining recording and a 10 -min segment was selected which appeared to be typical of motility patterns during this session. A peak was classified as any pen deflection of $2 \mathrm{~mm}$ or greater from baseline. Upward and downward pen deflections were classified as circular and longitudinal respectively. Longitudinal peak amplitude was also determined for each recording session and reported in terms of $\mathrm{mm}$ pen deflection from baseline. Because of its uniformity, circular muscle peak amplitude was not measured. Data were analysed by least squares using the Student-Neuman-Keuls multiple range test to separate means (SAS Institute Inc., SAS User's Guide: Statistics, 1982 edition). 


\section{Results}

Oviducal motility during the oestrous cycle

The successful implantation of these intraluminal transducers into the isthmus facilitated the measurement of oviducal motility in cycling dairy cattle. By comparing motility patterns recorded during similar stages of the oestrous cycle of different cows, the variations in motility patterns were correlated with the cyclic changes in progesterone during the oestrous cycle. Cyclic changes in patterns of oviducal motility are summarized for all recorded cycles in Table 2 with an example of one complete cycle in a single cow illustrated in Fig. 1.

Table 2. Mean ( \pm s.e.m.) longitudinal frequency (peaks $/ 10 \mathrm{~min})$, circular frequency (peaks/10 min) and longitudinal amplitude of oviducal motility during the oestrous cycle of cows

\begin{tabular}{lccc}
\hline $\begin{array}{l}\text { Period of } \\
\text { cycle }\end{array}$ & $\begin{array}{c}\text { Longitudinal muscle } \\
\text { frequency }\end{array}$ & $\begin{array}{c}\text { Circular muscle } \\
\text { frequency }\end{array}$ & $\begin{array}{c}\text { Longitudinal muscle } \\
\text { amplitude (mm) }\end{array}$ \\
\hline Dioestrus & $2 \cdot 3 \pm 1 \cdot 4^{\mathrm{a}}$ & $0 \cdot 4 \pm 1 \cdot 6^{\mathrm{a}}$ & $1 \cdot 0 \pm 0 \cdot 3^{\mathrm{a}}$ \\
Pro-oestrus & $9 \cdot 1 \pm 1 \cdot 4^{\mathrm{b}}$ & $0.9 \pm 1 \cdot 6^{\mathrm{a}}$ & $4 \cdot 0 \pm 0 \cdot 3^{\mathrm{b}}$ \\
Oestrus & $8 \cdot 8 \pm 2 \cdot 4^{\mathrm{b}}$ & $29 \cdot 2 \pm 2 \cdot 7^{\mathrm{b}}$ & $3 \cdot 0 \pm 0 \cdot 6^{\mathrm{b}}$ \\
Metoestrus & $13 \cdot 8 \pm 1 \cdot 4^{\mathrm{b}}$ & $0 \cdot 4 \pm 1 \cdot 5^{\mathrm{a}}$ & $3 \cdot 8 \pm 0 \cdot 3^{\mathrm{b}}$ \\
\hline
\end{tabular}

Means with different letters are significantly different $(P<0.05)$.
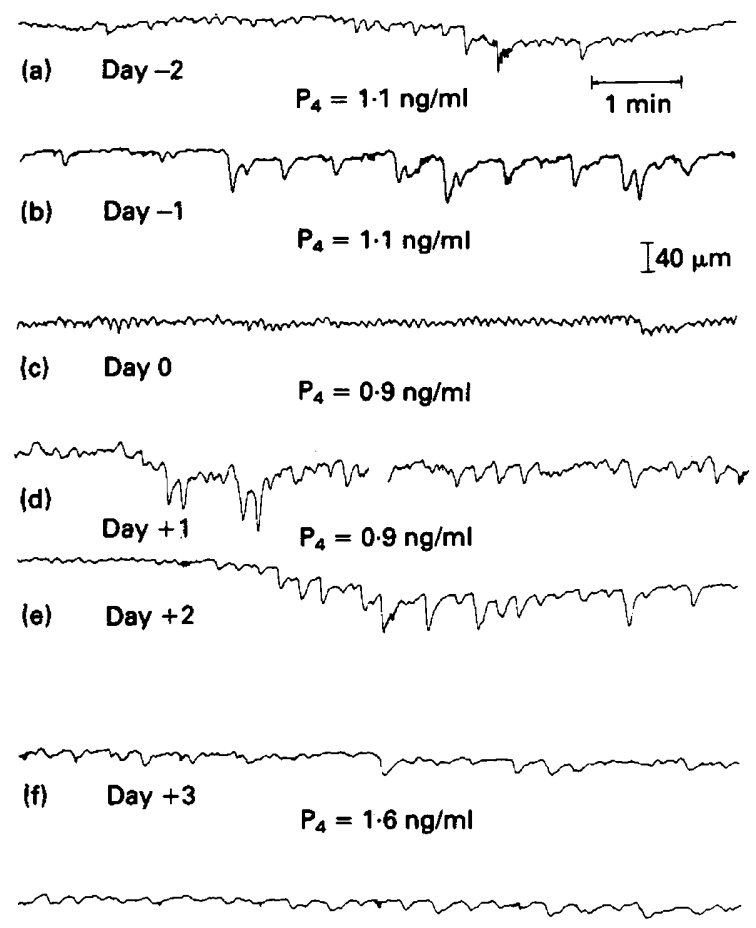

(g) Day +4

$$
P_{4}=2.6 \mathrm{ng} / \mathrm{ml}
$$

Fig. 1. Cyclic variations in patterns of right oviducal motility and mean progesterone $\left(P_{4}\right)$ concentrations from Cow 465 (Cycle 1). Oestrus is Day 0. Longitudinal and circular muscle contractions are characterized by downward (b, d and e) and upward (c) pen deflections, respectively. 
An increase $(P<0.05)$ in the spontaneous activity of the oviduct was observed $2-5$ days before the onset of behavioural oestrus and was identified as being due primarily to contraction of the longitudinal smooth muscle fibres (Figs 1a, b; Table 2). This increase in activity was accompanied by decreasing concentrations of progesterone in the peripheral blood. At 1-2 days before oestrus the amplitude and frequency of longitudinal muscle activity increased. During oestrus, oviducal contractions were of high frequency and low amplitude and were mainly identified as being due to contraction of circular fibres (Fig. 1c; Table 2). This pattern of activity varied little through the recording periods of the different cows. Circulating concentrations of progesterone were $<1.0 \mathrm{ng} / \mathrm{ml}$ plasma, confirming the regression of the corpus luteum.

Patterns of oviducal motility for 3-5 days after oestrus were similar to those during the 2-3-day period before oestrus (Figs 1d,e). Longitudinal muscle activity remained high and was accompanied by a decrease in circular muscle contractions (Table 2). From about 1 day before until 1 day after oestrus, activity was almost continuous. Outside of this range, short periods of low activity were seen between periods of pronounced activity. Progesterone concentrations remained low $(<1 \mathrm{ng} / \mathrm{ml}$ ) before increasing 3-5 days after oestrus (Figs If, g). This rise in plasma progesterone values was accompanied by a decrease in the frequency and amplitude of spontaneous muscle activity (Table 2).

\section{Bilateral patterns of oviducal motility}

The successful implantation of transducers in right and left oviducts of Cows 179 and 465 allowed comparison of motility patterns between the oviducts. Notable was the lack of synchrony between the right and left oviducts. In Cow 179 (Fig. 2), the left oviduct was more active during Cycles 1 and $2(P<0.05)$ with the right oviduct more active during Cycle $3(P<0.05)$. In the periods before and after oestrus of Cycle 2 (Figs $2 a-f$ ), the left oviduct showed a higher level of muscular activity, exhibiting a pattern of motility similar to that previously discussed. During Cycle 3, however, activity was greater during the period after oestrus in recordings from the right oviduct (Figs 2j-l). Rectal palpation of ovaries permitted association of greater activity in the oviduct ipsilateral to the active ovary during both cycles. The patterns of oviducal motility were asynchronous between oviducts during both cycles. A similar pattern of asynchrony of oviducal contractions was observed in Cow 465, in which the left oviduct was more active during Cycle 1 while the right oviduct was more active during Cycle $2(P<0.05)$. This animal was not palpated.

\section{Discussion}

The classification of oviducal motility in this study is based on the observations of Blair \& Beck (1977), who found in rabbits that the intraluminal transducers of the same type as used in this study were able to distinguish between circular and longitudinal patterns of activity. Additional cinematographic studies in rabbits have also compared tubal motion and chart recordings (W. D. Blair, personal communication). The transducers also have been compared with microballons in humans (W. D. Blair \& E. Coutinho, unpublished data) in which outbursts as measured by microballons were consistently associated with increases in transducer diameter. Careful analysis of these results suggested that outbursts were caused by contractions of the longitudinal muscle fibres of the oviduct and broad ligament. The findings of these studies suggested that circular muscle contractions decreased the internal diameter of the implanted transducers, resulting in upward pen deflections, while contraction of the longitudinal fibres resulted in an increase in transducer diameter and downward pen deflection. The contractions of the circular fibres were higher in frequency and lower in amplitude than contractions of the longitudinal fibres. These implanted transducers were able to pick up the increases in diameter of the lumen associated with smooth muscle contractions because they were prestressed, being slightly larger than the lumen. 


\section{Cycle 2}

(a) Day - 4

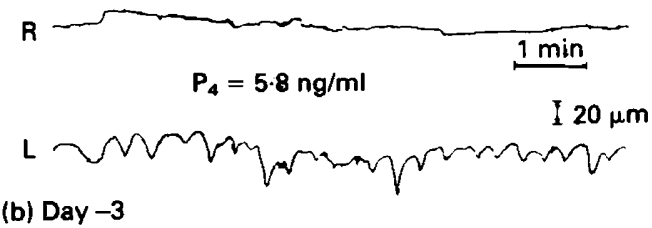

$\mathbf{R}$

$$
P_{4}=4.4 \mathrm{ng} / \mathrm{ml}
$$

L mormann

$\mathbf{R}$

(c) Day -2 $\quad P_{4}=3.9 \mathrm{ng} / \mathrm{ml}$

L

\section{Cycle 3}

(g) Day -5

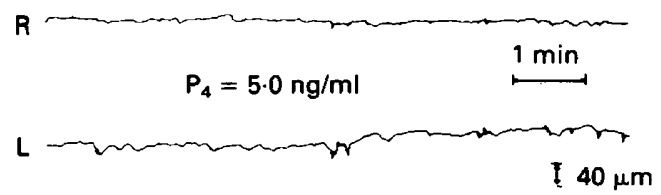

(h) Day -3

$$
\mathbf{R}
$$$$
P_{4}=2 \mathrm{ng} / \mathrm{ml}
$$

$$
\mathrm{L}
$$

(i) Day 0

I $40 \mu \mathrm{m}$

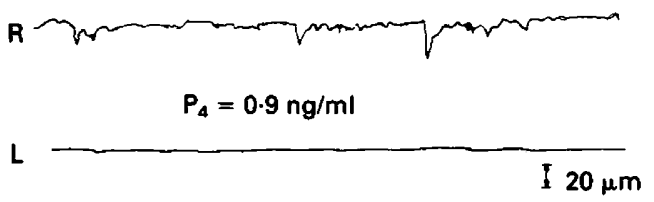

(d) Day +2

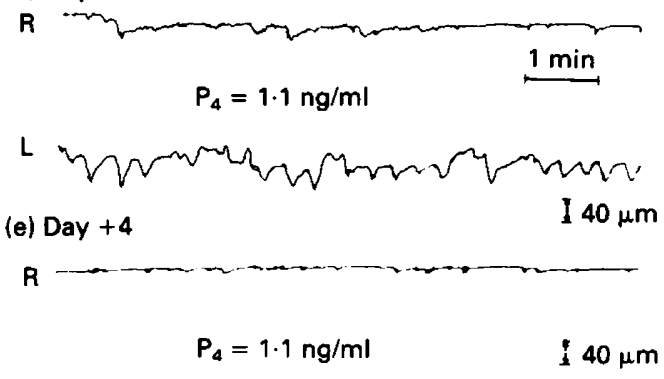

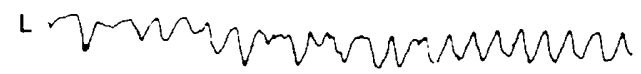

(f) Day +5

R

$$
P_{4}=2.7 \mathrm{ng} / \mathrm{ml}
$$

I $20 \mu \mathrm{m}$

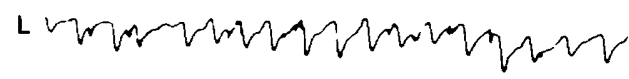

(j) Day +1

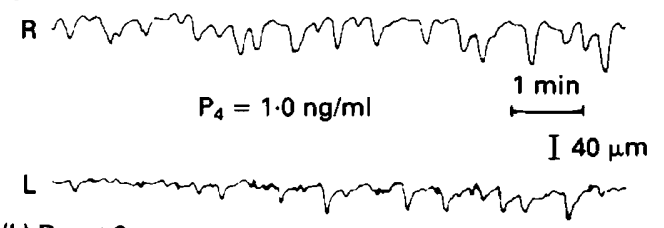

(k) Day +2

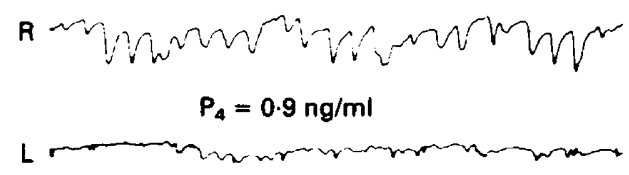

(I) Day +3

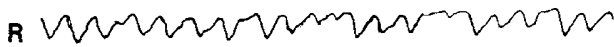

$P_{4}=1.5 \mathrm{ng} / \mathrm{ml}$

$\mathbf{L}$

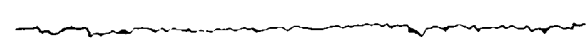

Fig. 2. Bilateral patterns of oviducal $\left(L=\right.$ left; $R=$ right) motility and progesterone $\left(P_{4}\right)$ concentrations from Cow 179 (Cycles 2 and 3). Oestrus is Day 0. Higher levels of activity were observed in the left oviduct (a-f) during Cycle 2 and in the right oviduct (i-1) during Cycle 3 .

In the present study, oviducal motility of the isthmic segment across different stages of the oestrous cycle was characterized. Little activity was seen during the luteal phase of the cycle. With luteal regression, as indicated by falling concentrations of progesterone, an increase in spontaneous activity was observed consisting mostly of low frequency, high amplitude-type muscle contractions 
previously associated with longitudinal fibres (Blair \& Beck, 1977). Motility increased 1-2 days before oestrus, becoming mixed with circular-type muscle activity $12-24 \mathrm{~h}$ before oestrus. During oestrus, frequency of circular activity increased compared to patterns before oestrus. Activity after oestrus was similar to that seen before oestrus with a decrease in both frequency and amplitude of activity occurring with increasing concentrations of circulating progesterone.

The extremely low level of activity observed from the cow oviduct during the luteal phase of the cycle concurred with studies in the human, rabbit and cow (Salomy \& Harper, 1971; Maia \& Coutinho, 1976; Ruckebusch \& Bayard, 1975). Increasing levels of motility observed 3-5 days before oestrus also confirmed the study of Ruckebusch \& Bayard (1975) who stated that the frequency and amplitude of oviducal contractions increased during pro-oestrus in the cow. Our ability to distinguish between increases and decreases in the diameter of the oviduct made further characterization of this activity possible with longitudinal-type muscle activity predominating during pro-oestrus. Increasing frequency of oviducal motility around the time of oestrus concurred with work reported in the rabbit and cow (Black \& Asdell, 1958; Greenwald, 1963; Ruckebusch \& Bayard, 1975; Talo \& Hodgson, 1978). That these contractions were of the circular type had not been reported previously. Contractions of circular muscle are implicated as major factors in the transport of spermatozoa to the ampullary site of fertilization (Black \& Asdell, 1958). Patterns of oviducal motility after oestrus were similar to those seen during the 3-5-day period before oestrus. While high levels of motility have been previously reported during the post-ovulatory periods of humans (Maia \& Coutinho, 1970), rabbits (Black \& Asdell, 1958) and cows (Ruckebush \& Bayard, 1975), our observations are unique in that we were able to identify this as primarily high-amplitude, low-frequency contractions which have been associated with longitudinal smooth muscle fibres previously. Although the bovine oviduct was known to possess both longitudinal and circular muscle layers, no previous attempts had been made to separate these patterns of activity. The results of this study show that both the type of oviducal motility in the isthmus as well as the total activity are related to the period of the oestrous cycle in cows. The high levels of longitudinal and circular activity concurrent with ovulation and sperm transport, respectively, suggest roles for these types of contractions in gamete transport. It would be interesting to ascertain if similar patterns of motility are seen in other segments of the oviduct.

The observation of asynchronous activity between right and left oviducts agreed with that of Ruckebusch \& Pichot (1975), who reported dissymmetry in spontaneous activity between oviducts in sheep. These researchers also reported a more intense response to adrenergic agonists by the active oviduct. No attempt was made to correlate this response to the functional status of the corresponding ovary. The general hypothesis concerning oviducal motility has stated that it is mediated by the ratios of oestrogens and progesterone that are released into the systemic circulation (Spilman et al., 1978). If these mediating factors are in the systemic circulation a bilateral synchronous stimulation of both oviducts would seem likely. Higher concentrations of these steroids in the vasculature of the oviduct ipsilateral with the active ovary could account for the greater amplitude of contractions in that oviduct but may not account for the asynchrony. Adsit (1982) has reported greater activity in the oviduct ipsilateral to the active ovary and such asynchronous motility could result from local factors exerted by the functional ovary or the ovum.

Contribution No. 6341, Mississippi Agricultural and Forestry Experiment Station.

\section{References}

Adsit, P.D. (1982) Computer analysis system for bovine motility data. M.S. thesis, Mississippi State University.

Abraham, G.E., Swerdlofi, R., Tulchinsky, D. \& Odell, W.D. (1971) Radioimmunoassay of plasma progesterone. J. clin. Endocr. Metab. 32, 619-624.
Black, D.L. \& Asdell, S.A. (1958) Transport through the rabbit oviduct. Am. J. Physiol. 192, 63-68.

Blair, W.D. \& Beck, L.R. (1977) In-vivo effects of prostaglandin $F_{2}$ alpha and $E_{2}$ on contractility and diameter of the rabbit oviduct using intraluminal transducers. Biol. Reprod. 16, 122-127. 
Blair, W.D., Gilliland, B.E. \& Sauer, B.W. (1976) An intra-luminal transducer/telemetry system for oviduct motility studies. J. appl. Physiol. 40, 999-1003.

Dobson, H., Hopkinson, C. \& Ward, W.R. (1972) Progesterone, $17 \beta$-oestradiol and luteinizing hormone in bovine peripheral plasma in relation to ovulation. $J$. Endocr. 55, i-iv.

Eddy, C.A. \& Black, D.L. (1974) Ovum transport through rabbit oviducts perfused with 6-hydroxydopamine. J. Reprod. Fert. 38, 189-191.

Eddy, C.A., Flores, J., Archer, D. \& Pauerstein, C.J. (1978) The role of cilia in infertility; an evaluation by selective microsurgical modification of the rabbit oviduct. Am. J. Obstet. Gynecol. 132, 814-821.

Greenwald, G.S. (1963) In vivo recordings of intraluminal pressure changes in the rabbit oviduct. Fert. Steril. 14, 666-674.

Maia, H. \& Coutinho, E. (1970) Peristalsis and antiperistalsis of the human fallopian tube during the menstrual cycle. Biol. Reprod. 2, 305-314.

Maia, H. \& Coutinho, E. (1976) Motility of the human oviduct in vivo. In Ovum Transport and Fertility Regulation, pp. 221-227. Eds M. J. Harper, C. J.
Pauerstein, C. E. Adams, E. M. Coutinho, H. B. Croxatto \& D. M. Patton. Scriptor, Copenhagen.

Rodriguez-Martinez, H., Einarsson, S. \& Larsson, B. (1982) Spontaneous motility of the oviduct in the anaesthesized pig. J. Reprod. Fert. 66, 615-624.

Ruckebusch, Y. \& Bayard, F. (1975) Motility of the oviduct and uterus of the cow during the oestrous cycle. J. Reprod. Fert. 43, 23-32.

Ruckebusch, Y. \& Pichot, D. (1975) Effects of adrenergic drugs on sheep oviduct motility. Eur. J. Pharm. 33, 193-196.

Salomy, M. \& Harper, M.J.K. (1971) Cyclic changes of oviduct motility in rabbits. Biol. Reprod. 4, 185.

Spilman, C.H., Shikh, A.A. \& Harper, M.F.K. (1978) Oviductal motility, amplitude and ovarian steroid secretion during egg transport in the rabbit. Biol. Reprod. 18, 409-417.

Talo, A. \& Hodgson, B.J. (1978) Spike bursts in the rabbit oviduct. I. Effect of ovulation. Am. J. Physiol. 234, 439-443.

Received 3 August 1987 